\title{
A preventive approach to risk management in global fruit and vegetable supply chains
}

\author{
V. Raab ${ }^{1}$, J. O’Hagan ${ }^{1}$, F. Stecher ${ }^{1}$, M. Fürtjes ${ }^{1}$, A. Brügger ${ }^{2}$, \\ M. Bratzler ${ }^{2}$, B. Wibbe ${ }^{2} \&$ B. Petersen ${ }^{1}$ \\ ${ }^{1}$ Department of Preventive Health Management, \\ University of Bonn, Germany \\ ${ }^{2}$ Deutscher Fruchthandelsverband (German Fruit Trade Association) \\ (DFHV) eV, Germany
}

\begin{abstract}
The aim of this empirical study was to create a concept for the implementation of a proactive risk management system in global value-added chains for fruit and vegetables. The focus was to develop a proposal for the categorisation of risks, as well as the systematisation of preventive failure identification and evaluation. This paper presents a general process model of how the quality management tool "Failure Mode and Effects Analysis" (FMEA) can be used for the implementation of preventive measures in the international food trade. Furthermore, a proposal was developed for using existing information from food control databases of the competent public authorities in supplier countries as the initial guidelines for developing supplier and risk assessment procedures.

Keywords: risk management, crisis management, risk prevention, health management, global supply chains, fruit and vegetable, enterohaemorrhagic Escherichia coli (EHEC).
\end{abstract}

\section{Introduction}

A wide variety of fresh fruit and vegetables is made available throughout the year by the food retail and wholesale sectors. As a result, the fruit and vegetable trade has become steadily more and more international - but at the same time risks have increased regarding the safety of the product. While in Europe, the keystone for over 10 years has been the existing food law (EU (VO) 178/2002), similar regulations are absent in many non-European countries [1]. Provisions 
are made in the basic regulations for extensive tests that should exclude biological, chemical and physical risks to the consumer - these come under the aegis of the producer, as well as complying with the requirements of the trade. Raab et al. [2] describe a number of approaches for companies in the agricultural and food industry which can be linked together within an integrated management system and that are concerned with methods for ensuring acceptable quality and efficient risk management. In the DIN ISO 31000 [3] risk is defined as follows: "A risk can be considered as the description of an event with potentially adverse effects". In another definition that is particularly relevant for the food chain, Jantke [4] states - "the risk reflects the extent of the failure to achieve the aim of a criterion or desired characteristic (e.g. product safety) in the production process and presents itself with the occurrence of the hazard". Food safety and the prevention of risks is in effect related to the increasing number of targets and processes concerned with food production and the food trade (e.g. food freezing, food quality, animal health, drug use, feed safety, animal welfare, plant protection, environmental protection, biodiversity, sustainability, population growth, globalisation) (Figure 1) [5].

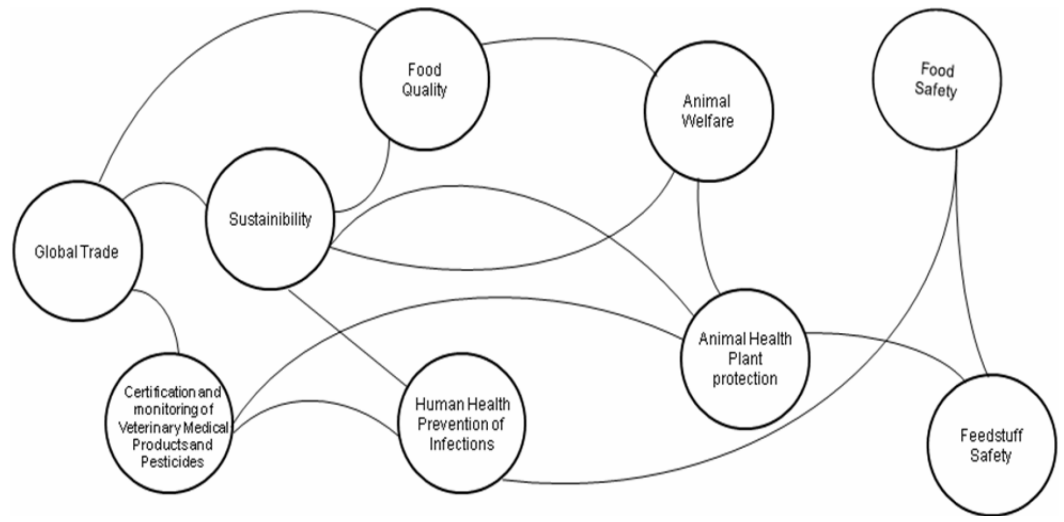

Figure 1: Links between food safety and other objectives concerned in the production of, and trading in, food (presented according to [5]).

The linkages illustrated imply at the same time that functions relevant to risk management can also be divided into a range of differing areas of the law and of responsibilities (e.g. environmental law, animal welfare law, pharmaceutical law). The production of fruit and vegetables in Europe and beyond, as well as the marketing of these products (through to the final distribution stages and finally to the consumer), is characterised (to a large degree) by multi-level, geographically and organisationally distributed value-added chains and branches [5]. Concerted steps in quality and risk management and the development of a combined audit strategy of the production of food (from its production through to retail grocery) thus require further innovation potential to come from global companies and relevant organisations [6]. In addition to the traditional criteria, such as reliability and fast delivery - additional characteristics including rapid crisis management, 
networking, communication skills and intercultural skills are required within the value chain.

For many years extensive testing has been undertaken in the fruit and vegetable trade area to uncover hazards and to develop measures to obviate and/or minimise them. Nevertheless, the fruit and vegetable trade itself and consumers in Europe generally became particularly alarmed in the summer of 2011 by the enterohaemorrhagic Escherichia coli (EHEC) crisis in Germany. This crisis made clear in particular that, both in the incoming inspection of fresh produce, as well as in the operation of the official monitoring systems, the microbiological risks had not been adequately considered. Overall, more than 3,800 people were infected with EHEC, and 855 people suffered from the associated gastroenteritis and the haemolytic uraemic syndrome, of whom 53 died [7].

A month earlier, there was much disquiet in the Netherlands when it became known that in various vegetables, (including those normally consumed raw), resistant ESBL (extended-spectrum beta-lactamase) producing bacteria were found [8]. These two food-related crises show that the importance of testing strategies regarding microbial risks was underestimated.

Following on from this background, the subsequent research questions are posed:

- How can the preventive quality management method FMEA support a structured approach to risk assessment?

- Which testing strategies can be integrated according to the type of hazard into supplier assessment strategies?

- What interfaces to existing global monitoring systems and databases can be defined (or be better defined) in order to improve risk communication?

The aim of the study was to develop (with the assistance of information gained from structured expert interviews) a process model for early risk identification and risk evaluation with respect to the trade in fruit and vegetables and to establish criteria for the selection of suitable test strategies.

\section{Methodology}

The development of the concept was carried out in four steps, using a range of methods and tools.

In the four stages (see Figure 2), a range of differing methods and tools was used which have been adapted to the issues involved within the fruit trade. A tree diagram was used to categorise health risks. Failure Mode and Effects Analysis (FMEA) with appropriate risk assessment tables provided the framework for a structured expert survey. The required database has been compiled through the use of various qualitative and quantitative survey techniques. The questionnaire is structured as follows: the first key area is used for the determination of risk categories. The second key area is used to assist experts to evaluate hazards and 


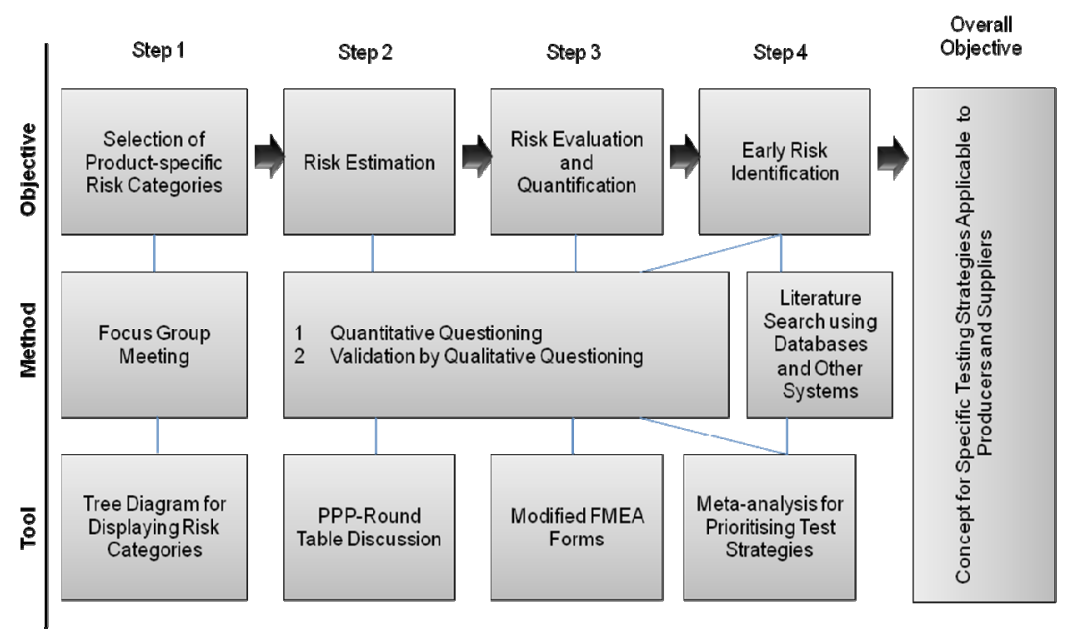

Figure 2: $\quad$ Stages in developing the concept.

risks (based on the underlying principle in the FMEA of the prioritisation of the occurrences, meanings and probabilities of detection). The third key area concerns the recommended type and frequency of inspections and the underlying test plans based on the individual risk categories referred to. In addition, a database analysis was performed so as to ascertain the degree of implementation of early warning systems in different regions of production and steps along the value-added chain. 30 different expert opinions from the business and scientific fields have been incorporated in the survey of experts, in the context of the focus group meeting, as well as in the qualitative survey.

\section{Procedure model for supplier- and product-specific risk management}

A four-stage process model of risk management measures in global value chains of fruits and vegetables has been developed based on research and interviews with experts.

Stages in the proposed model:

1. Selection of product-specific risk categories;

2. Selection of forms/questionnaires for risk assessment based on supplier countries, companies or individual process steps;

3. Risk assessment and ranking using risk priority numbers (RPN);

4. Selection of testing and risk minimisation strategies.

For all four stages, in addition to the quality management tools (tree diagram and FMEA) questionnaires have been developed, which can be used in predefined steps to assess risks. The steps build on each other, thus leading to a systematic risk prevention approach on the basis of the pre-defined risk 
categories and the risk assessments undertaken. An overview of the individual steps and the respective questionnaires and evaluation documents in a structured and systematic risk assessment is shown in Table 1.

\section{Stage 1: selection of product-specific risk categories}

For risk assessment along the value chain the division into the main categories (chemical, physical and microbiological) is relevant which leads to the corresponding finely detailed structure involving these categories. The tree diagram in Figure 3 shows a rough overview of the fruit and vegetable trade in the relevant main and subcategories.

\section{Stage 2: selection of standard questionnaires for risk assessment based on supplier countries, companies or individual process stages}

Based on the results of the quantitative and qualitative survey, a range of different indicators have been assessed and several evaluation schemes for riskbased assessment have hence been defined (see Table 1). Table 2 below illustrates exemplarily how an evaluation based schema for the determination of the risk priority number of different types of deficiencies along all stages of the supply chain can be formulated.

\section{Stage 3: risk assessment and ranking using the RPN}

Based on the first two steps of the model, at this stage the necessary measures are shown which need to be taken in each case after the ranking of risks. The priority actions are defined on the basis of the underlying aspects in the previous steps (probability of occurrence, importance and probability of detection) and the resulting risk priority number (RPN). If the calculated value of the RPN exceeds 29 , it is recommended that optimisation measures should be put into action (see Table 3). Which measures should be taken depends on the individual values of the RPN. For example, the probability of occurrence of a potentially large error (risk score 4 or 5), methods should be applied immediately that reduce the probability of its occurrence. Typically, this would involve the improvement of on-farm hygiene measures and/or the introduction of regular staff training. In contrast, if the probability of detecting a potential hazard is low (risk score 4 or 5), procedures should be used to increase this probability. This could involve increasing the frequency of inspections and/or improving or expanding the testing methods employed. In order to take account of risks with serious health consequences for the consumer, for risks with the highest significance level ( $\mathrm{B}=$ 5) - immediate action and crisis management measures are defined (see Table 3). In the cases where there is recognition of harmful incidents that have already occurred, as well as the altering of testing strategies, particular emphasis needs to be put on crisis communication within the supply chain, and simultaneously with regulatory agencies. The way these communications can be coordinated has been described in the $\mathrm{A}^{3} \mathrm{M}$ approach $[9,10]$. 


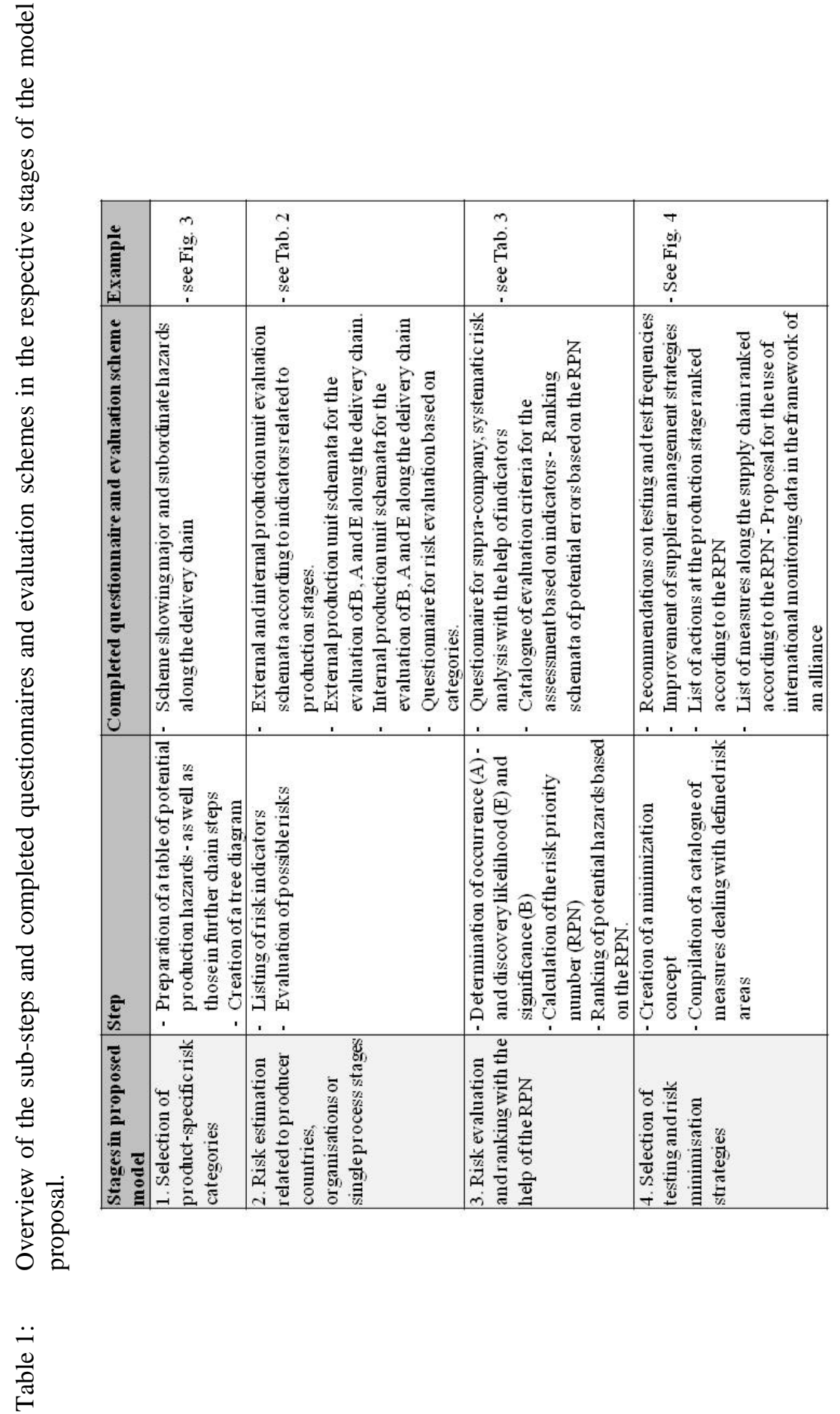

WIT Transactions on Ecology and The Environment, Vol 170, () 2013 WIT Press www.witpress.com, ISSN 1743-3541 (on-line) 


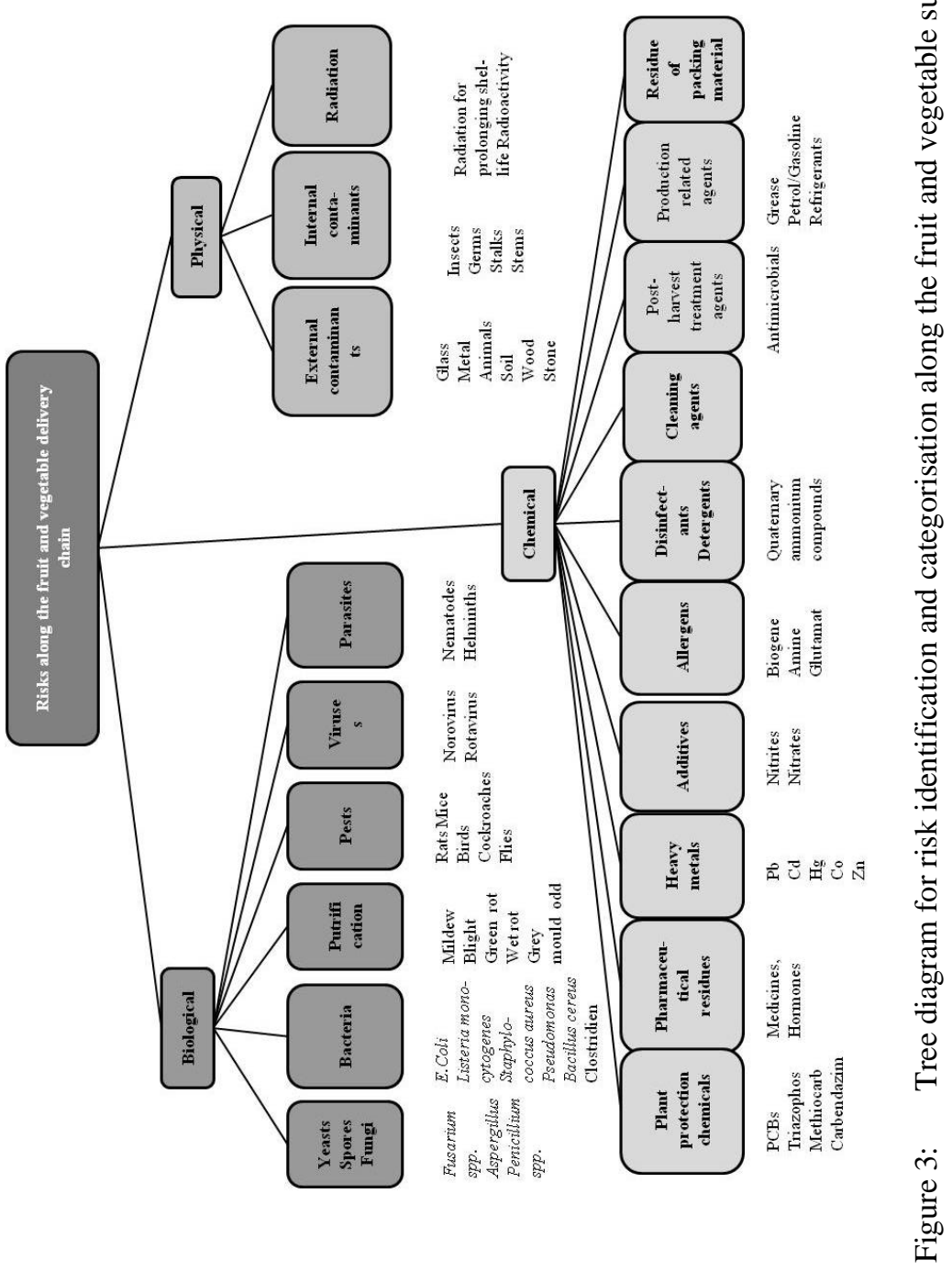




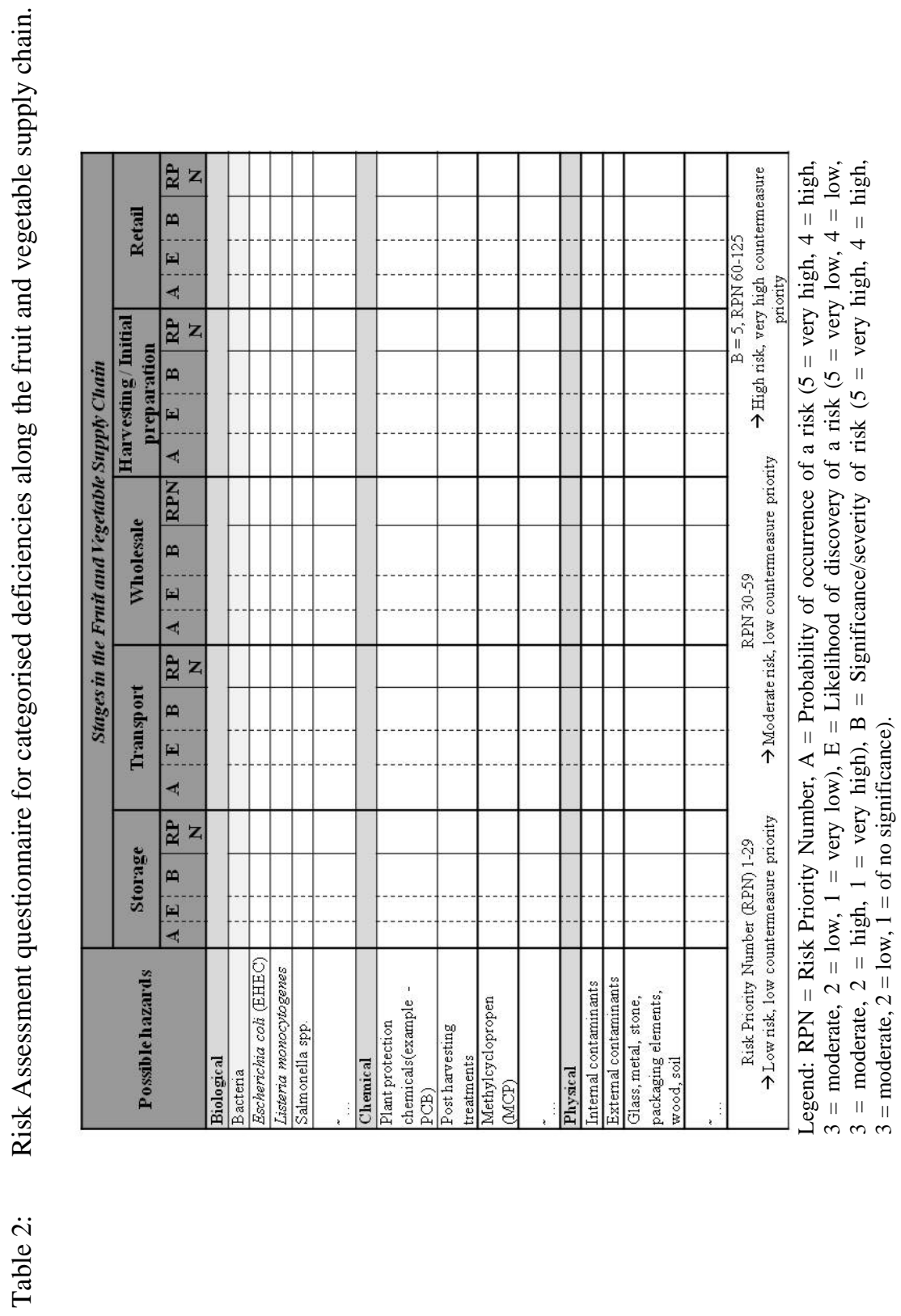


Table 3: Ranking of potential hazards taking into account their RPN, as well as B.

\begin{tabular}{|c|c|c|c|c|}
\hline & \multicolumn{3}{|c|}{ RPN } & \multirow{2}{*}{$\frac{B}{5}$} \\
\hline & $1-29$ & $30-59$ & $60-125$ & \\
\hline Risk & low & moderate & very high & very high \\
\hline $\begin{array}{l}\text { Need for } \\
\text { counter- } \\
\text { measures }\end{array}$ & low & moderate & needs rapid attention & $\begin{array}{l}\text { needs immediate } \\
\text { attention }+ \text { the } \\
\text { introduction of a } \\
\text { measures for dealing } \\
\text { with the crisis }\end{array}$ \\
\hline Testing & maintain & $\begin{array}{l}\text { increase testing } \\
\text { frequency }\end{array}$ & $\begin{array}{l}\text { alteration of testing } \\
\text { strategy }\end{array}$ & $\begin{array}{l}\text { Altered testing } \\
\text { strategy needed }+ \\
\text { extended crisis } \\
\text { communications } \\
\text { within the scope of } \\
\text { the } \mathrm{A}^{3} \mathrm{M} \text { approach }\end{array}$ \\
\hline \multicolumn{5}{|c|}{$\begin{array}{c}\text { RPN }=\text { Risk priority number }=1-125 \\
\mathrm{~B}=\text { Significance of a potential hazard or result of a hazard. }\end{array}$} \\
\hline
\end{tabular}

\section{Stage 4: selection of test and risk minimisation strategies}

Based on the assessed priority measures within the model, various actions are suggested for improving testing methods, optimising recommended test frequencies and improving supply chain management strategies. In addition to the measures listed in the ranked (according to RPN) improvements catalogue, a proposal is made for efficient use of monitoring data in collaboration with global alliances. The focus consequently is on the use of the defined indicators for early risk detection and the use of global data for monitoring purposes. The establishment of interfaces to global datasets of physical, chemical and biological risks and the regular manual monitoring of these databases is a way to identify risks proactively. However the databases are somewhat limited in that they only contain, usually methods, such as how one can identify microorganisms etc., or the threshold values for contaminants and residues. Where no thresholds have yet been established, but experts consider certain substances to be harmful, it makes sense to adopt the measures proposed by Schulze Althoff, et al. [11] as regards a minimisation concept. Figure 4 shows the core elements and responsibilities in the different phases of a minimisation concept.

It is of the highest importance that both - official regulatory/testing bodies and enterprises involved - ensure that (through the use of innovative production, and transportation and marketing processes), threshold values set for the trade are not be exceeded. This is to be achieved by the combined collection and use of collected data and involves the joint setting of threshold values. Risk 


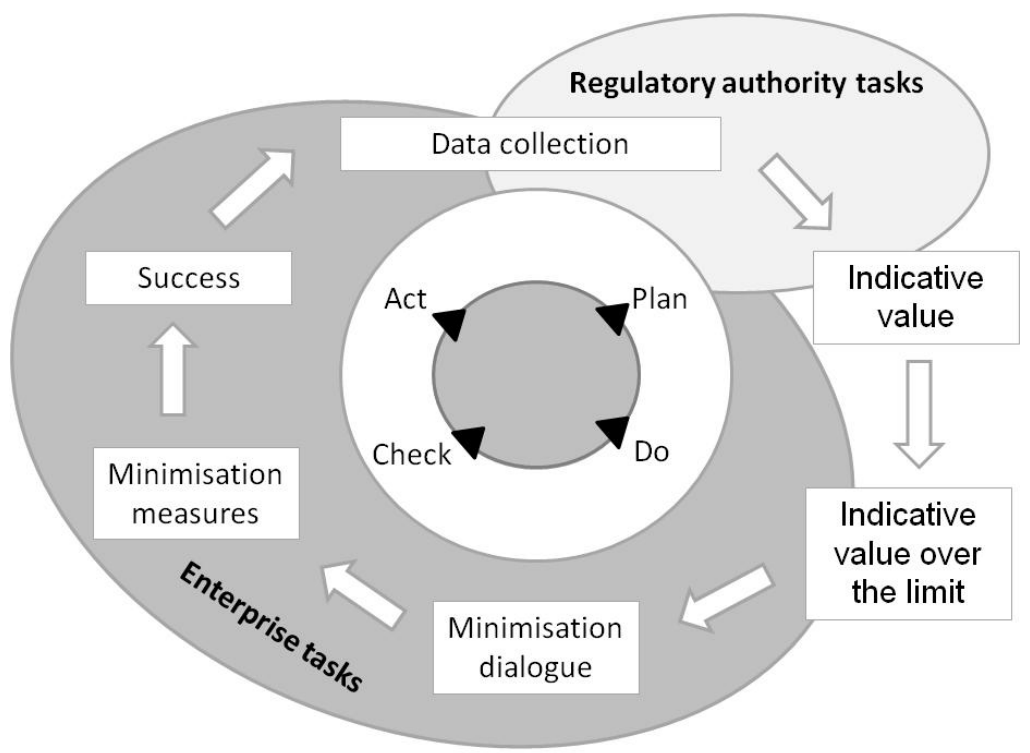

Figure 4: Key elements and responsibilities in the various phases of a minimisation concept [11].

communication plays an important and specific role in the whole range of crisis prevention and crisis management. Against this background, in recent years, further minimisation concepts have been presented in which the organisation of collaboration between different stages of the value chain regarding inspection strategies (AMOR approach) play a special role including cooperation between industry and public authorities so as to ensure effective crisis management [12].

\section{Summary}

In recent decades, the overall framework and the responsibilities for preventive consumer protection have changed significantly in the fruit and vegetable trade, as well as in other food sectors. The need for appropriate and specific tools and procedures for the selection of suppliers and the evaluation of both rare and common risks in the fruit and vegetable trade has grown appreciably. The outlined process model represents a concept, by the use of which, companies in the sector and in related organisations can establish a systematic risk assessment framework. In four steps it is shown how (with the help of the preventive quality management FMEA method):

1. Product-specific risk categories can be identified.

2. Risk assessment (based on supplier countries, companies and process steps) can be undertaken.

3. Using the risk priority number, a ranking of potential hazards can be made.

4. Test strategies can be developed. 


\section{Acknowledgements}

This article has been published in the German language in the proceedings of the GQW conference 2013 in Berlin:

Verena Raab; Friederike Stecher; Melanie Fürtjes; Andreas Brügger; Barbara Wibbe and Brigitte Petersen (2013): Konzept zum präventiven Risikomanagement in globalen Wertschöpfungsketten von Obst und Gemüse. In: Roland Jochem und Dominik Rößle (eds.): Qualitätsmanagement nachhaltig gestalten und umsetzen. Bericht zur GQW-Jahrestagung 2013 in Berlin, Band 15/2013. Shaker Verlag, Aachen. ISBN 978-3-8440-1700-7, pp. 271-290.

The authors express their gratitude to the Shaker Publishing House Aachen for granting permission for the English language rights.

\section{References}

[1] Leible, S.; Ortiges, F.; Schäfer, S. (2013): Gesetzliche Anforderungen. In: Qualitätsmanagement in der Agrar- und Ernährungswirtschaft, Eds.: Petersen, B.; Nüssel, M.; Symposion Publishing GmbH, Düsseldorf, p. 49-62.

[2] Raab, V.; Petersen, B.; Bruckner, S; Lehnert, S.; Theuvsen, L. (2013): Empfehlung zur Weiterentwicklung des Qualitätsmanagements. In: Qualitätsmanagement in der Agrar- und Ernährungswirtschaft, Eds.: Petersen, B.; Nüssel, M.; Symposion Publishing GmbH, Düsseldorf, p. 231271.

[3] ISO - International Organisation for Standardization (2009): Risk Management Principles and Guidelines. ISO 31000:2009.

[4] Jantke, C. (2006): Operative Risiken in Schlachtung und Fleischverarbeitung: Risikoanalyse und Konzept eines Risikomanagementsystems. Dissertation, School of Management, Technische Universität München.

[5] Wilke, T.; Raab, V.; Breuer, O.; Hamer, M.; Petersen, B. (2013): Lebensmittelsicherheit und die Entwicklung von Public-PrivatePartnership-Strukturen. In: Zeitschrift für Außen- und Sicherheitspolitik 6 (1).

[6] Petersen, B.; Nüssel, M. (2013): Qualitätsmanagement in der Agrar- und Ernährungswirtschaft, Symposion Publishing GmbH, Düsseldorf, 231 pages.

[7] Robert Koch-Institut (2011). Report: Abschließende Darstellung und Bewertung der epidemiologischen Erkenntnisse im EHEC O104:H4 Ausbruch, Berlin.

[8] Appel, B.; Böl, G.-F.; Greiner, M.; Lahrssen-Wiederholt, M.; Hensel, A. (2011): EHEC-Ausbruch 2011 - Aufklärung des Ausbruchs entlang der Lebensmittelkette. BfR-Wissenschaft, Berlin, Heft 4.

[9] Slütter, S.; Wilke, T.; Pinior, B.; Breuer, O.; Petersen, B. (2012): Support in crisis communication by forming a strategic alliance in information 
management on the example of the German pork production chain. Presentation at the "Food Safety Management Conference 2012", Campden, UK.

[10] Petersen, B.; Raab, V. (2013): Qualitätswissenschaftenals Querschnittsdisziplin. In: Qualitätsmanagement in der Agrar- und Ernährungswirtschaft, Eds.: Petersen, B.; Nüssel, M.; Symposion Publishing GmbH, Düsseldorf, p. 69-116.

[11] Schulze Althoff, G.; Schulpin, C.; Schmitz-Eiberger, M.; Petersen, B. (2007): Einführung von dynamischen Minimierungsansätzen für Rückstände in Frischeprodukten. In: Journal für Verbraucherschutz und Lebensmittelsicherheit (Journal of Consumer Protection and Food Safety), p. 20-23.

[12] Lang, J.; Petersen, B. (2012): AMOR - improving inspection strategies in agri-food supply chains. 22 ${ }^{\text {nd }}$ Annual IFAMA World Forum and Symposium, “The Road to 2050: The China Factor”, Shanghai, China, June 11-14, 2012. 